\title{
Effect of Magnetic Field Applied along Hard Axis on Current-Induced Magnetization Switching in $\mathrm{CoFeB} / \mathrm{MgO} / \mathrm{CoFeB}$ Magnetic Tunnel Junctions
}

\author{
T. Inokuchi ${ }^{* * * *}$, Y. Saito ${ }^{*, * * *}$, H. Sugiyama*,,*** , and K. Inomata ${ }^{* *, * * *}$ \\ "Corporate R\&D Center, Toshiba Corp., 1 Komukai-Toshiba-cho, Saiwai-ku, Kawasaki 212-8582, Japan \\ ${ }^{* *}$ National Institute for Materials Science, 1-2-1 Sengen, Tsukuba 305-0044, Japan \\ ${ }^{* * *}$ CREST, Japan Science and Technology Agency, 4-1-8 Honcho Kawaguchi, Saitama 332-0012, Japan
}

\begin{abstract}
The dependence of critical current density $\left(J_{c}\right)$ for current-induced magnetization switching (CIMS) on external magnetic fields applied along the hard axis of a free layer $\left(H_{\text {hard }}\right)$ was investigated in $\mathrm{CoFeB} / \mathrm{MgO} / \mathrm{CoFeB}$ magnetic tunnel junctions. The $J_{\mathrm{c}}$ and the intrinsic current density $\left(J_{\mathrm{c} 0}\right)$, which is derived from the dependence of $J_{\mathrm{c}}$ on pulse duration, decreased as $\left|H_{\text {hard }}\right|$ increased. As the reduction ratios of $J_{\mathrm{c} 0}$ while applying $H_{\text {hard }}$ depend on the anisotropy field of junctions $\left(H_{\mathrm{k}}\right)$, the initial angle of magnetization, affected by $H_{\text {hard }}$ and $H_{\mathrm{k}}$, is related to the reduction in $J_{c 0}$. These results are discussed in terms of the energy barrier for CIMS and the spin transfer efficiency.
\end{abstract}

Key words: magnetic tunnel junction, current-induced magnetization switching

\section{$\mathrm{CoFeB} / \mathrm{MgO} / \mathrm{CoFeB}$ トンネル接合における スピン注入磁化反転に対する困難軸方向磁場の影響

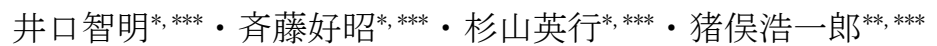 \\ *（株）東芝 研究開発センター，川崎市幸区小向東芝町 1（†212-8582） \\ **物質・材料研究機構，つくば市千現 1-2-1（テ305-0047） \\ ${ }^{* * *}$ 科学技術振興機構, 川口市本町 4-1-8（产332-0012）}

\section{1.はじめに}

近年, MRAM (Magnetic Random Access Memory) などのス ピントロニクスデバイスの磁化書き込み法としてスピン注入磁化 反転法 ${ }^{1,2)}$ が注目されている. スピン注入磁化反転法では, 磁気記 録層ヘスピン偏極した電子を注入することにより磁気記録層の磁 化方向を反転させる. この磁化反転を生じさせるために必要な電 流は, 磁気記録層の全磁気モーメント, 異方性磁界, 磁気記録層 と磁気固着層のスピン偏極率，ダンピング係数，および，外部印 加磁界などに依存する ${ }^{1)}$. 磁気記録層のサイズが小さくなると, 磁 気記録層の全磁気モーメントが減少するため, スピン注入磁化反 転に必要な臨界電流は下がる.一般に, 素子サイズが $200 \mathrm{~nm} \phi$ 以 下のときに，スピン注入磁化反転法は電流磁界を用いた磁化反転 法よりも低電流で書き込みが可能であると言われている ${ }^{3)}$.

しかしながら，スピン注入磁化反転には $10^{7} \mathrm{~A} / \mathrm{cm}^{2}$ のオーダー の非常に大きな臨界電流密度 $\left(J_{\mathrm{c}}\right)$ を要する ${ }^{4)}$. 最近では, スピン 反射層の付与 ${ }^{5,6,7)}$ や $\mathrm{CoFeB}$ 磁気記録層を用いる ${ }^{8)}, \mathrm{MgO}$ トンネ ルバリアを用いる ${ }^{9-12)}$ などの手法を用いることで, $10^{6} \mathrm{~A} / \mathrm{cm}^{2}$ の才 ーダーの J が実現されているものの，MRAM の書き込み方法と して用いるためには $10^{6} \mathrm{~A} / \mathrm{cm}^{2}$ 以下の $J_{\mathrm{c}}$ で, かつ, 熱擾乱而性定 数 $\left(K_{\mathrm{u}} V k_{\mathrm{B}} T\right) 80$ 以上を達成する必要がある. そのため, さらな る Jの低減法の確立が望まれている.

以前，本グループでは MTJ (Magnetic Tunnel Junction) の困 難軸方向への磁場 $\left(\left|H_{\text {hard }}\right|\right)$ の印加による J 削減法を報告した ${ }^{13,14)}$. また，別グループからはGMR（Giant Magnetoresistance）素子 における $J_{\mathrm{c}}$ の困難軸方向磁場依存性も報告されている ${ }^{15,16)}$. 本手 法の概要は以下の通りである.

まず, $\left|H_{\text {hard }}\right|$ の印加による磁気記録層の静磁エネルギーの変化 を考える. 一軸異方性エネルギー $K_{\mathrm{u}}$ とゼーマンエネルギーのみを 考えると, 静磁工ネルギー $E_{\text {static }}$ の磁化角度 $(\theta)$ 依存性は以下
の式で表される.

$$
E_{\text {static }}(\theta)=K_{\mathrm{u}} \sin ^{2} \theta+M_{\mathrm{s}} \text { Hhard } \cos \theta
$$

上式功, $\left|H_{\text {hard }}\right|$ の印加とともに $\theta=90^{\circ}$ もしくは $270^{\circ}$ に存在す るエネルギー障壁 $E\left(=\operatorname{Max} .\left(E_{\text {static }}(\theta)\right)-\operatorname{Min} .\left(E_{\text {static }}(\theta)\right)\right)$ が 減少することがわかる. 寸ると， $J_{\mathrm{c}}$ の $E$ 依存性は以下の(2)式で表 される17) ために, $E$ の減少とともに $J_{\mathrm{c}}$ は減少寸ると考えられる.

$$
J_{\mathrm{c}}=J_{\mathrm{c} 0}\left[1-(k \mathrm{~B} T / E) \ln \left(t_{\mathrm{p}} / \tau_{0}\right)\right] \quad\left(t_{\mathrm{p}} \gg \tau_{0}\right)
$$

ここで，政 はスピン歳差運動の周期， t ス幅が $\tau_{0}$ のときの $J_{c}, k_{\mathrm{B}}$ はボルツマン定数, $T$ は $\mathrm{MTJ}$ の温度 である.

また, $J_{\mathrm{c}}$ の| $H_{\mathrm{hard}} \mid$ 依存性として次の要因も考えられる.いま, $J_{\mathrm{c} 0}$ に対する磁化の初期角度 $\theta$ の影響は次式で表される ${ }^{11}$.

$$
J_{\mathrm{c} 0} \propto\left(1+p^{2} \cos \theta\right) /(p / 2)
$$

すなわち, $\theta$ が増加するとスピン注入効率が増大するため に $J_{\mathrm{c} 0}$ は減少する. $\left|H_{\mathrm{hard}}\right|$ を印加すると, (1)式から磁化 の安定点, すなわち, 最小の $E_{\text {static }}(\theta)$ をとる $\theta$ は $0^{\circ}$ もしくは $180^{\circ}$ からずれることがわかる．したがって， $\left|H_{\text {hard }}\right|$ の印加により $\theta$ が増加してスピン注入効率が増 大するために $J_{\mathrm{c} 0}$ は減少し, 結果的に $J_{\mathrm{c}}$ も減少するもの と考えられる. 以上の要因をまとめると, $\left|H_{\text {hard }}\right|$ の印加 により $E$ および $J_{\mathrm{c} 0}$ が減少し, 結果的に $J_{\mathrm{c}}$ の減少がもた らされるものと考えられる.

今回，本グループで異方性磁場 $H_{\mathrm{k}}$ の異なる MTJ を用いて J の| $H_{\text {hard }}$ 依存性を調べたところ, 新たな知見が得られたので, そ の内容について報告する.

\section{2. 実験方法}

本研究で使用した MTJ の構造は Ta / Ru / IrMn / $\mathrm{CoFe} / \mathrm{Ru} /$ $\mathrm{CoFeB} / \mathrm{MgO} / \mathrm{CoFeB} / \mathrm{Ta}$ である. 磁気固着層として用いた下部 
$\mathrm{CoFeB}$ の膜厚は $4 \mathrm{~nm}$, 磁気記録層として用いた上部 $\mathrm{CoFeB}$ の膜 厚は $2 \mathrm{~nm}$ である. MTJ の作製にはフォトリソグラフィー，反応 性イオンエッチング, Arイオンミリング等を用いた. なお，接合 のサイズを規定する部分にはレジストのスリミング処理を行い， 最終的に $0.00426 \sim 0.164 \mu \mathrm{m}^{2}$ の接合面積を有する素子を作製し た.

$R-H$ 曲線の測定には，4端子直流抵抗測定法を用いた. スピン 注入磁化反転は，パルス電流を試料に印加した後に低い読み出し 電流を用いて4端子直流抵抗測定を行う手順を繰り返しおこなつ て測定した. 読み出し電流值は, 試料に印加される電圧が $10 \mathrm{mV}$ になるように設定している。また，測定の際にはジュール発熱が スピン注入磁化反転におよぼす影響を避けるために，パルス電流 印加の間隔を $100 \mathrm{~ms}$ 以上に設定した. 以上の測定を行う際に $H_{\text {easy }}$ および $H_{\text {hard }}$ を印加している。なお、 $H_{\text {easy }}$ の印加では平均の臨界 電流密度 $J_{\mathrm{c}}\left(=\left(J_{\mathrm{C}}^{\mathrm{P} \rightarrow \mathrm{AP}}-J_{\mathrm{C}}^{\mathrm{AP}} \rightarrow \mathrm{P}\right) / 2\right)$ は变わらないと報告され ている $1,17,18)$ ため、今回の実験では $H_{\text {easy }}$ を固定して $H_{\text {hard }}$ 依存性 を測定した. また， $H_{\mathrm{k}}$ はアステロイドカーブが閉じる $H_{\mathrm{hard}}$ の值 から求めた.

\section{3. 実験結果および考察}

\section{1 困難軸磁場印加下でのスピン注入磁化反転の観測}

Fig. 1(a)に $H_{\mathrm{k}}$ が 150 Oe の試料（Sample 1) を用いて測定し た $R-H$ 曲線を示す. 本試料の RA (Resistance-Area product) は $6 \Omega \cdot \mu \mathrm{m}^{2}, \mathrm{MR}$ 比 (Magnetoresistance ratio) は $65.0 \%$, 接合 面積は $0.064 \mu \mathrm{m}^{2}$ である. 次に, $H_{\text {easy }}=-72 \mathrm{Oe},\left|H_{\mathrm{hard}}\right|=0 \mathrm{Oe}$ において幅 $1 \mathrm{~ms}$ のパルス電流を用いてスピン注入磁化反転を観 測した結果を Fig. 1(b)に示す．まず，MTJに印加するパルス電流 の振幅を一 方向に増大させていくと, $J_{\mathrm{c}}^{\mathrm{AP} \rightarrow \mathrm{P}}=-2.2 \times 10^{6} \mathrm{~A} / \mathrm{cm}^{2}$ で AP (Anti-Parallel) 状態から P (Parallel) 状態へのスイッチ ングが観測された. 次に, パルス電流の振幅を+方向に増加させて いくと, $\int_{\mathrm{c}}^{\mathrm{P} \rightarrow \mathrm{AP}}=+3.4 \times 10^{6} \mathrm{~A} / \mathrm{cm}^{2}$ で $\mathrm{P}$ 状態から $\mathrm{AP}$ 状態へのスイ ッチングが観測された. これらの電流密度から平均の臨界電流密 度 $J_{\mathrm{c}}\left(=\left(J_{\mathrm{c}}^{\mathrm{P} \rightarrow \mathrm{AP}}\right.\right.$ - $\left.\left.J_{\mathrm{c}}^{\mathrm{AP} \rightarrow \mathrm{P}}\right) / 2\right)$ を見積もると, $2.8 \times 10^{6} \mathrm{~A} / \mathrm{cm}^{2}$ と なる. このスピン注入磁化反転で観測された抵抗変化は, $R-H$ 曲 線で観測された抵抗変化と等しいことから，スピン偏極した電子
によって完全に磁化が反転していると考えられる.

次に, $H_{\text {easy }}=-72$ Oe, $\left|H_{\text {hard }}\right|=100$ Oeにおいて, 幅 $1 \mathrm{~ms}$ のパルス電流を用いてスピン注入磁化反転を観測した結果を Fig. 2 に示寸. $J_{\mathrm{c}}^{\mathrm{AP} \rightarrow \mathrm{P}}$ は $-2.1 \times 10^{6} \mathrm{~A} / \mathrm{cm}^{2}, \quad J_{\mathrm{c}}^{\mathrm{P} \rightarrow \mathrm{AP}}$ は $+2.6 \times 10^{6}$ $\mathrm{A} / \mathrm{cm}^{2}$ であり，これらの值から見積もった $J_{c}$ は $2.4 \times 10^{6} \mathrm{~A} / \mathrm{cm}^{2}$ であった.つまり, $\left|H_{\text {hard }}\right|$ の印加によって $J_{c}$ が低減した. なお,

$\left|H_{\text {hard }}\right|$ を印加すると磁化の安定状態が $0^{\circ}$ もくは $180^{\circ}$ から ずれるために, $\left|H_{\text {hard }}\right|=0$ Oe のときに比べると P 状態と AP 状 態の間の抵抗变化量が小さくなる. しかしながら， $\left|H_{\text {hard }}\right|=100$ Oe の印加下においてもスピン注入磁化反転で観測された抵抗変 化量は $R H$ 曲線で観測された抵抗変化量に等しいことを確認し ている.

この $\left|H_{\text {hard }}\right|$ の印加に伴う $J_{\mathrm{c}}$ 減少の起源を明らかに するために，Jc のパルス幅依存性を測定した（Fig. 3).こ のパルス幅依存性に対して(1)式を用いてフィッテングを 行い, $J_{\mathrm{c} 0}$ および 平均のエネルギー障壁高さ $E / K_{\mathrm{B}} T(=$ $\left.\left(E^{\mathrm{AP} \rightarrow \mathrm{P}}+E^{\mathrm{P} \rightarrow \mathrm{AP}}\right) / 2 K_{\mathrm{B}} T\right)$ を求めた. なお, ここでは $\tau_{0}$ を $10^{-9} \mathrm{~s}$ としている. その結果, $\left|H_{\mathrm{hard}}\right|=0$ Oe において $J_{\mathrm{c} 0}$ $=4.2 \times 10^{6} \mathrm{~A} / \mathrm{cm}^{2}$ かつ $E / K_{\mathrm{B}} T=49.7$ であったのに対し, $\left|H_{\text {hard }}\right|=100$ Oeにおいては,$\quad J_{\mathrm{c} 0}=3.4 \times 10^{6} \mathrm{~A} / \mathrm{cm}^{2}$ かつ $E / K_{\mathrm{B}} T=43.9$ であることがわかった.つまり, $\left|H_{\text {hard }}\right|$ の 印加とともに $J_{\mathrm{c} 0}$ は減少, かつ, $E / K_{\mathrm{B}} T$ も減少すること が明らかになった。この結果から，| $H_{\text {hard }} \mid$ の印加による $J_{\mathrm{c}}$ の低減は, $J_{\mathrm{c} 0}$ の減少と $E / K_{\mathrm{B}} T$ の減少に起因すると考 えられる。

\section{2 困難軸磁場印加下でのスピン注入磁化反転の試料依存} 性

次に, $H_{\mathrm{k}}$ の異なる試料について $J_{\mathrm{c}}$ の| $H_{\mathrm{hard}}$ | 依存性を 調べた.一例として, Fig. 4 に $H_{\mathrm{k}}$ が 40 Oe の試料 (Sample 2）を用いて $J_{\mathrm{c}}$ の $\left|H_{\mathrm{hard}}\right|$ 依存性を調べた結果を示す. 本 試料では, $H_{\text {easy }}=-22 \mathrm{Oe},\left|H_{\text {hard }}\right|=21 \mathrm{Oe}$ のとき, $J_{\mathrm{c} 0}=$ $3.2 \times 10^{6} \mathrm{~A} / \mathrm{cm}^{2}$, かつ, $E / K \mathrm{~B} T=32.3$ であるのに対し, $H_{\text {easy }}=-22 \mathrm{Oe},\left|H_{\mathrm{hard}}\right|=31$ Oe のとき $J_{\mathrm{c} 0}=2.6 \times 10^{6}$ $\mathrm{A} / \mathrm{cm}^{2}$, かつ, $E / K_{\mathrm{B}} T=27.1$ である.つまり, $10 \mathrm{Oe} の$ $\left|H_{\text {hard }}\right|$ の増加により, $J_{\mathrm{c} 0}$ は 0.8 倍になっている. 先程の Sample 1 においては, 100 Oe $の\left|H_{\mathrm{hard}}\right|$ の増加でも $J_{\mathrm{c} 0}$ は 0.8 倍にしかならなかったことに比べると, Sample 2 で
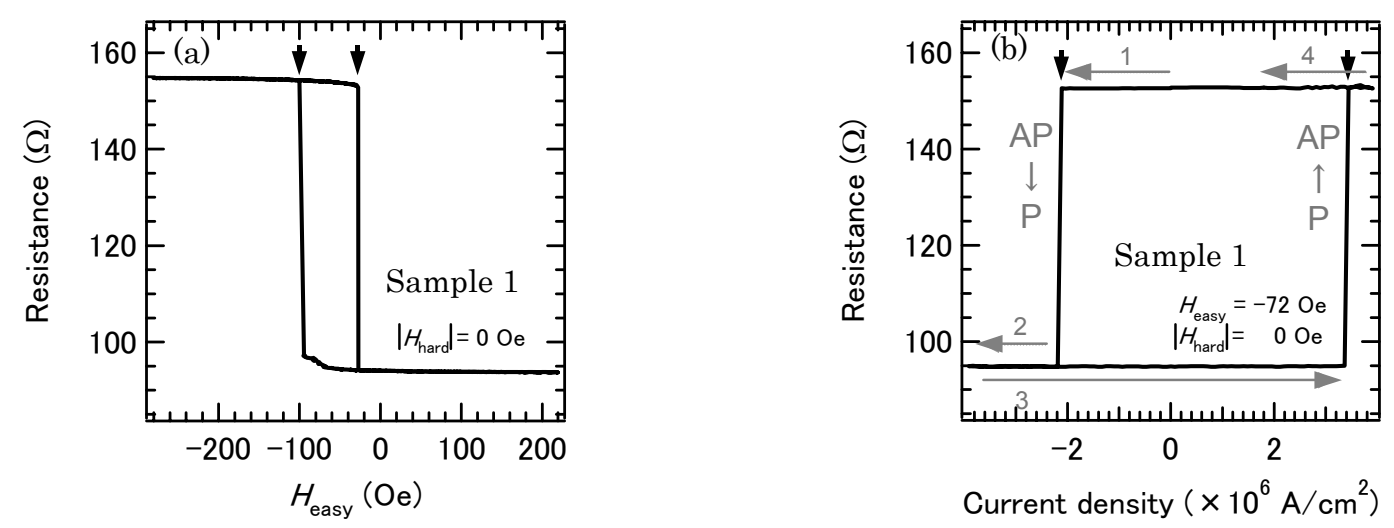

Fig. 1 (a) Magnetoresistance curve of MgO-based MTJ as a function of magnetic field applied along the easy axis of the MTJ $\left(H_{\text {easy }}\right)$ when the magnetic field along the magnetization hard axis of the MTJ $\left(H_{\text {hard }}\right)$ is 0 Oe. (b) Current-induced magnetization switching of the MTJ when $\left|H_{\text {hard }}\right|$ is 0 Oe and $H_{\text {easy }}$ is -72 Oe. 


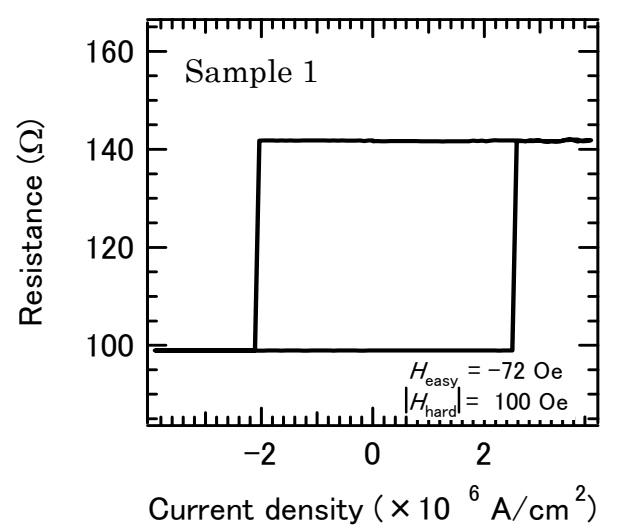

Fig. 2 Current-induced magnetization switching of the MTJ when $\left|H_{\text {hard }}\right|$ is 100 Oe and $H_{\text {easy }}$ is -72 Oe, measured using a junction with $H_{\mathrm{k}}$ of 150 Oe (Sample 1).

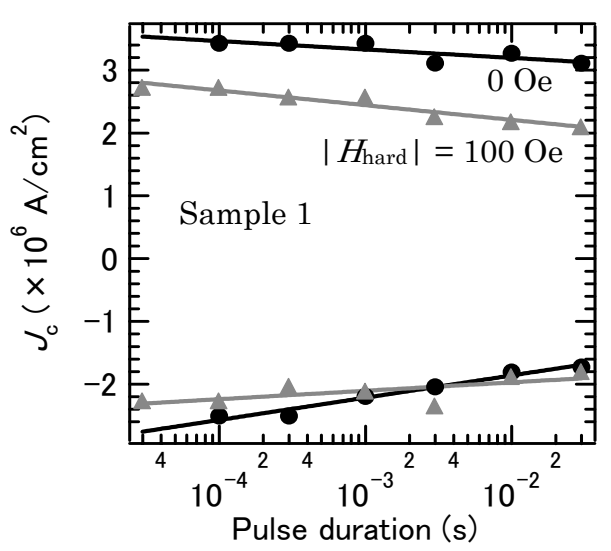

Fig. 3 Dependence of $J_{c}$ on pulse current duration when $\left|H_{\text {hard }}\right|=0$ Oe and 100 Oe, measured using a junction with $H_{\mathrm{k}}$ of 150 Oe (Sample 1).

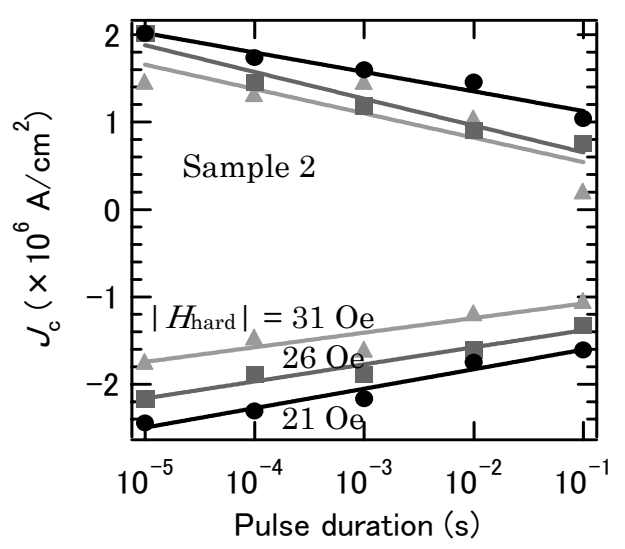

Fig. 4 Dependence of $J_{c}$ on pulse current duration when $\left|H_{\text {hard }}\right|=21$ Oe, 26 Oe, and 31 Oe, measured using a junction with $H_{\mathrm{k}}$ of 40 Oe (Sample 2).

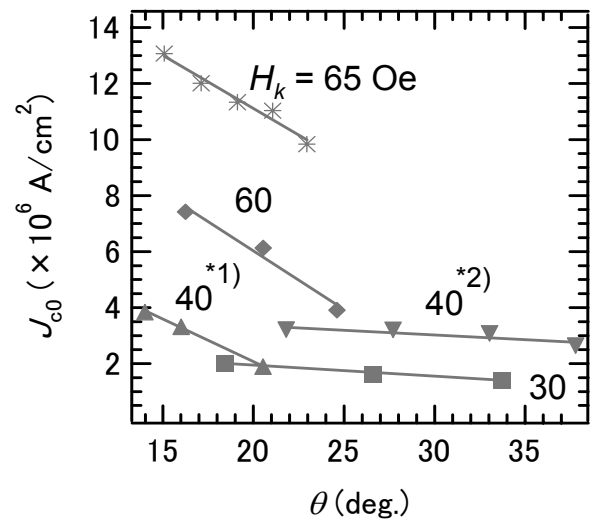

Fig. 5 Dependence of $J_{\mathrm{c} 0}$ on the initial angle $(\theta)$ of magnetization, measured using five different junctions with various anisotropy fields.

は $J_{\mathrm{c} 0}$ の| $H_{\text {hard }}$ | 依存性が大きい.

では, $J_{c 0}$ の| $H_{\text {hard }} \mid$ 依存性の起源について次のモデルを用いて 考えてみる. まず, 単磁区モデルを仮定すると, スピン注入磁化 反転をおこなう前の磁気記録層の磁化は以下の式で表される初期 角度 $\theta$ を向いていると考えられる.

$$
\theta=\tan ^{-1}\left(H_{\text {hard }} / H_{\mathrm{k}}\right)
$$

すなわち, この $\theta$ は $H_{\mathrm{hard}}$ と $H_{\mathrm{k}}$ がな寸角度であり, スピン注入 磁化反転を行う前の磁化の角度は, $\mathrm{P}$ 状態の場合には $\theta, \mathrm{AP}$ 状 態の場合には $180^{\circ}-\theta$ であると考えられる. 式(3)に従えば, こ の $\theta$ の増加により $J_{00}$ は減少するはずである. したがって, 大き な $H_{\mathrm{k}}$ を有する試料では $H_{\mathrm{hard}}$ の印加に伴う $\theta$ の変化が小さい ために，Jc0 の $H_{\mathrm{hard}}$ 依存性が小さくなると予想される.

そこで， $H_{\mathrm{k}}$ が $30 \mathrm{Oe}, 40 \mathrm{Oe}^{\left.*_{1}\right)} ， 40 \mathrm{Oe}^{\left.*^{2}\right)} ， 60 \mathrm{Oe}, 65 \mathrm{Oe} の$ 試料を用いて $J_{00}$ の $\left|H_{\text {hard }}\right|$ 依存性を測定した. その結果を, 式 (4)で表される $\theta$ を横軸としてプロットした結果を Fig. 5 に示す. この図から $\theta$ の増大に伴って $J_{00}$ は単調に減少することがわか る. この結果は, $\left|H_{\text {hard }}\right|$ の印加によって磁化の初期角度が平行 もしくは反平行からずれることによってスピン注入効率が増大し， $J_{00}$ が減少するという描像を強く支持しているものと考えられる. また, 磁化の初期角度の小さい領域 $\left(\theta<20^{\circ}\right)$ では, $J_{c 0}$ の $\theta$ 依 存性が大きいのに対し, 初期角度の大きな領域 $\left(\theta>20^{\circ}\right)$ では, $J_{00}$ の $\theta$ 依存性が小さい. すなわち，磁化の初期角度を $0^{\circ}$ も くは $180^{\circ}$ からわずかに傾けることにより $J_{00}$ を有効に削減でき ることを示唆している.

さて、式(3)に従えばFig. 5 の $J_{00}$ の $\theta$ 依存性は $\cos \theta$ で表され るはずである。つまり， $\theta$ が増大するにしたがい，J00 の減少率は さらに大きくなるはずであるが，観測された結果は $\cos \theta$ の依存 性には従わないように見える。なお、最近 Slonczewski により提 案されたモデル19) では，定電圧下におけるスピントルクは $\sin \theta$ に従うと予想されているが，これも Fig. 5 に表した結果とは一致 しない.この理論と実験結果の不一致は, 磁気記録層のドメイン 構造の影響などに起因寸るのではないかと考えているが，詳細な 


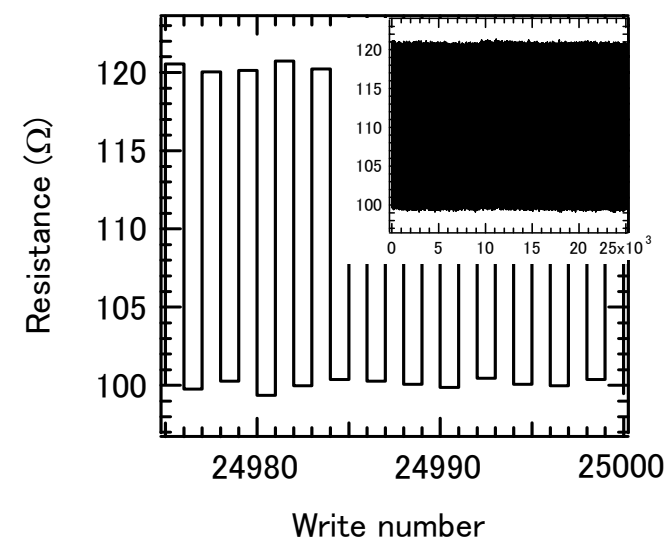

Fig. 6 Repeated measurement by using current-induced magnetization switching over 25000 times. The write current density was $\pm 1.8 \times 10^{6} \mathrm{~A} / \mathrm{cm}^{2}$ and the pulse duration was $100 \mu \mathrm{s}$.

\section{理解は今後の課題としたい.}

次に, | Hhard | 印加下でスピン注入書き込みを繰り返し行った 結果を Fig. 6 に示す．本測定におけるパルス幅は $100 \mu \mathrm{s}$ ，書き込 み電流密度は土 $1.8 \times 10^{6} \mathrm{~A} / \mathrm{cm}^{2},\left|H_{\text {hard }}\right|=15 \mathrm{Oe}$ である. また, $H_{\mathrm{k}}=30 \mathrm{Oe}$ ，接合面積は $0.164 \mu \mathrm{m}^{2}$ である。 25000 回の書き込み に対して, 誤書き込みは全く観測されなかった. すなわち, $\left|H_{\text {hard }}\right|$ の印加によって書き込み電流密度を下げることができるとともに, その条件下で安定な書き込み特性を実現できることが判明した. なお， $0.00426 \sim 0.164 \mu \mathrm{m}^{2}$ の接合面積を有する試料においても $\left|H_{\text {hard }}\right|$ の印加下で安定した書き込み特性を確認している 20).

最後に, $\left|H_{\mathrm{hard}}\right|$ の印加による $J_{\mathrm{c}}$ 削減法を実際のデバイ スに応用する例を紹介する，スピン注入磁化書き込み方式 の MRAM の利点の 1 つとして電流磁場配線が不要である ことが挙げられる。したがって，| $H_{\text {hard }} \mid$ を印加するため に別途電流磁場配線を設けるのは望ましくない，そこで， スピン注入磁化書き込み電流から発生する磁場を MTJ に 印加するデバイス構造（Fig. 7(a)）21）を利用する方法が考 えられる. 本構造では, 書き込み電流を印加した際にビッ 卜線および下部電極から発生される磁場を MTJ の磁化容 易軸に印加する. MTJ の向きを $90^{\circ}$ 回転させると, 書き 込み電流から発生される磁場を MTJ の磁化困難軸に印加 することができるが, この方法では半選択の問題が生じる. すなわち，書き込みを行いたい箇所以外のセルにも磁場が 印加されてしまい, そのセルの熱擾乱耐性が低下してしま う. その問題を解消する手段として, 先程のデバイス構造 に上部電極とビアを追加する方法が考えられる. その構造 を Fig. 7(b) に示す. 本構造では, ビット線から発生される 磁場の隣接セルに及ぼす影響が小さいために，半選択の問 題を回避することができる.

本構造において, MTJ から上部配線までの距離を $45 \mathrm{~nm}$, (a)

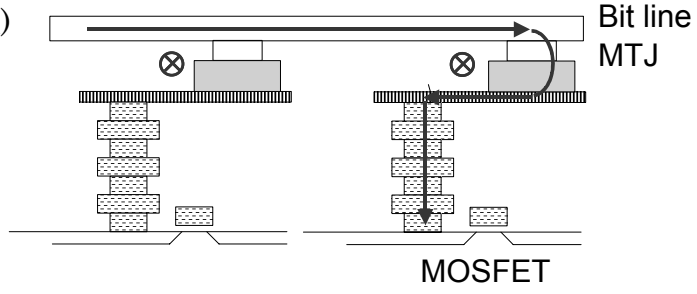

(b)

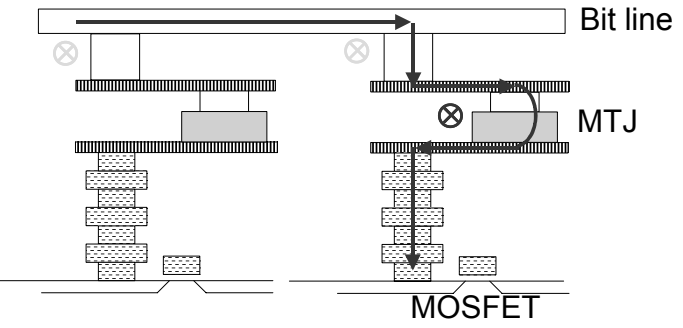

Fig. 7 (a) Device structure for applying $H_{\text {hard }}$ to MTJ by using write current ${ }^{21}$. (b) Improved device structure for applying $H_{\text {hard }}$ to MTJ by using write current. This structure can avoid half-selection problem.

MTJ のサイズを $100 \times 200 \mathrm{~nm}$ とし, 書き込み電流密度を $1 \times 10^{6} \mathrm{~A} / \mathrm{cm}^{2}$ とした場合, 発生される磁場強度は $29 \mathrm{Oe}$ と なる。例えば， $H_{\mathrm{k}}$ が 80 Oe の MTJ に対して式(4)を用い て磁化の初期角度を計算すると $19.9^{\circ}$ となるため, この磁 場によって書き込み電流密度を効果的に下げられるものと 考えられる.

なお，本実験では容易軸方向の磁界シフト分を打ち消す ために $H_{\text {easy }}$ を印加しているが, 実際のデバイスを作製する 際には, Synthetic antiferromagnet 層の膜厚比を変える, もしくは，エッチング量の制御などの方法で打ち消すこと ができる。

\section{4. まとめ}

電流誘起磁化反転における臨界電流密度（ $J_{\mathrm{c}} ）$ の困難軸 方向磁場（| $\left.H_{\text {hard }} \mid\right)$ 依存性を観測した。 その結果，J゙ は $\left|H_{\text {hard }}\right|$ の増加に伴って減少することを見出した．また， $J_{\mathrm{c}}$ のパルス幅依存性から見積もった $J_{\mathrm{c} 0}$ は| $H_{\text {hard }} \mid$ の増 加に伴って減少することを見出した．この $J_{\mathrm{c} 0}$ の減少の起 源を明らかにするために, $H_{\mathrm{k}}$ の異なる試料について $J_{\mathrm{c} 0}$ の 測定を行ったところ，J J $J_{\mathrm{c} 0}$ の減少は $\left|H_{\mathrm{hard}}\right|$ の増加に伴う $\theta$ の増加でよく説明できることが判明した．すなわち， J $J_{\mathrm{c} 0}$ の減少は $\theta$ の増加によるスピントランスファー効率の増 大に起因するものと考えられる.

\section{References}

1) J. C. Slonczewski: J. Magn. Magn. Mater., 159, L1 (1996). 2) L. Berger: Phys. Rev. B, 54, 9353 (1996).

3) K. Yagami and Y. Suzuki: J. Magn. Soc. Jpn., 28, 937 (2004).

4) Y. Huai, F. Albert, P. Nguyen, M. Pakala, and T. Valet: Appl. Phys. Lett., 84, 3118 (2004).

5) Y . Jiang, T. Nozaki, S. Abe, T. Ochiai, A. Hirohata, N. Tezuka, 
and K. Inomata: Nat. Mater., 3, 1 (2004).

6) K. Yagami, A. A. Tulapurkar, A. Fukushima, and Y. Suzuki: Appl. Phys. Lett., 85, 5634 (2004).

7) Y. Huai, M. Pakala, Z. Diao, and Y. Ding: Appl. Phys. Lett., 87, 222510 (2004)

8) M. Hosomi, H. Yamagishi, T. Yamamoto, K. Bessho, Y. Higo, K. Yamane, H. Yamada, M. Shoji, H. Hachino, C. Fukumoto, H. Nagao, and H. Kano: Electron Devices Meeting, 2005. IEDM Technical Digest, p. 459.

9) H. Kubota, A. Fukushima, Y. Ootani, S. Yuasa, K. Ando, H. Maehara, K. Tsunekawa, D. D. Djayaprawira, N. Watanabe, and Y. Suzuki: Jpn. J. Appl. Phys., 44, L1237 (2005).

10) J. Hayakawa, S. Ikeda, Y. M. Lee, R. Sasaki, T. Meguro, F. Matsukura, H. Takahashi, and H. Ohno: Jpn. J. Appl. Phys., 44, L1267 (2005).

11) H. Kubota, A. Fukushima, Y. Ootani, S. Yuasa, K. Ando, H. Maehara, K. Tsunekawa, D. D. Djayaprawira, N. Watanabe, and Y. Suzuki: Appl. Phys. Lett., 89, 032505 (2006).

12) J. Hayakawa, S. Ikeda, Y. M. Lee, R. Sasaki, T. Meguro, F. Matsukura, H. Takahashi, and H. Ohno: Jpn. J. Appl. Phys., 45, L1057 (2006).
13) T. Inokuchi, H. Sugiyama, Y. Saito, and K. Inomata: IEEE INTERMAG 2006 Technical Digests, p.267.

14) T. Inokuchi, H. Sugiyama, Y. Saito, and K. Inomata: Appl. Phys. Lett., 89, 102502 (2006)

15) T. Devolder, K. Ito, J. A. Katine, P. Crozat, J. Kim, M. J. Carey, and C. Chappert: IEEE INTERMAG 2006 Technical Digests, p.4.

16) T. Devolder, P. Crozat, J.-V. Kim, C. Chappert, K. Ito, J. A. Katine, and M. J. Carey: Appl. Phys. Lett., 88, 152502 (2006).

17) R. H. Koch, J. A. Katine, and J. Z. Sun: Phys. Rev. Lett., 92 , $088302(2004)$

18) D. Lacour, J. A. Katine, N. Smith, M. J. Carey, and J. R. Childress: Appl. Phys. Lett., 85, 4681 (2004).

19) J. C. Slonczewski: Phys. Rev. B, 71, 024411 (2005).

20) Y. Saito, T. Inokuchi, H. Sugiyama, K. Inomata: International Workshop on Spin Transfer, p. 129

21) W. C. Jeong, J. H. Park, J. H. Oh, G. T. Jeong, H. S. Jeong, and K. Kim: Symp. on VLSI Tech., p. 184 (2005)

2006年10月18日受理，2007年1月23日採録 